ISSN: 2224-0616

Int. J. Agril. Res. Innov. \& Tech. 8 (1): 70-78, J une, 2018

Available online at http:// www.ijarit.webs.com

\title{
PEOPLE'S PERCEPTION ON AGRICULTURAL VULNERABILITIES TO CLIMATE CHANGE AND SLR IN BANGLADESH: ADAPTATION STRATEGIES AND EXPLANATORY VARIABLES
}

\author{
M.A. Islam ${ }^{*}$ and S.K. Paul ${ }^{2}$ \\ Received 23 April 2018, Revised 16 June 2018, Accepted 26 June 2018, Published online 30 June 2018
}

\begin{abstract}
The objective of this research is to evaluate people's perception on vulnerabilities of agriculture and to explore effective adaptation options with identifying the underlying demographic, socio-economic and other relevant variables that influence the adaptation strategies in the sea level rise (SLR) hazard induced coastal areas of Bangladesh. The study finds that climate change and induced SLR are emerging threats to coastal agriculture of Bangladesh; hence, farmers are applying different adaptation strategies to reduce the vulnerabilities of coastal agriculture. Selection of effective adaptation strategies to vulnerabilities of agriculture depends not only on the magnitude, intensity and the impacts of climate change and SLR, but also perceptions and types of farmer, land, educational level, indigenous knowledge about adaptation, locational advantages, external support, community awareness and sharing of different effective mechanisms among the farmers. Effective adaptation strategies with high perceptions have significant influence to reduce the vulnerabilities of agriculture considering the adverse impacts of climate change and SLR. In time of extreme climatic hazards when a great loss in agriculture hamper the coastal agrobased economy, different effective indigenous local adaptation strategies through farmer awareness and community co-operation become vital for minimizing the impact of climatic hazards and reducing the vulnerabilities of coastal agriculture.
\end{abstract}

Keywords: Agriculture, Vulnerability, Climate Change, SLR, Adaptation Strategies

${ }^{1}$ Department of Geography and Environment, Shahjalal University of Science and Technology, Sylhet-3114, Bangladesh.

${ }^{2}$ Department of Geography and Environmental Studies, University of Rajshahi, Rajshahi-6205, Bangladesh.

*Corresponding author's email: anowar.ru@gmail.com (M.A. Islam)

\section{Introduction}

Bangladesh is one of the largest deltas in the world, which is highly vulnerable to natural disasters because of its geographical location, flat and low-lying landscape, population density, poverty, illiteracy, lack of institutional setup etc. Impact of climate change in Bangladesh is an extremely crucial issue considering its physical and socio-economic conditions, and Bangladesh is one of the most vulnerable nations to the impacts of global climate change in the coming decades (ADB, 1994; IPCC, 2001; Brammer, 2014). Vulnerabilities in agriculture as a main economic activity of the peoples of Bangladesh and necessity of the adaptation measures to reduce these vulnerabilities considering the poor socio-economic conditions is now a hot topic in global communities.

SLR along the coast of Bangladesh is a critical variable that may amplify the vulnerability to global climate change (IPCC, 2001; Rabbani et al., 2015). Global climate change induced SLR have adverse impacts to the coastal agriculture of
Bangladesh especially in terms of the area of inundation, salinity intrusion and reduction in crop production (Paul and Routray, 2010; Brammer, 2014). The area of agricultural land, production of crops, sustainability of the local crop varieties, income and employment facilities of the farmers is also highly vulnerable to various climate change and SLR hazards (Karim and Mimura, 2008; Islam et al., 2015). However, despite having highly vulnerability to SLR, the coastal agriculture of Bangladesh may be sustained with the increasing of SLR by taking proper adaptive measures (Huq et al., 1996; Karim et al., 1999; Paul and Routray, 2011).

Earlier studies dealing with agricultural vulnerabilities and adaptation options are narrowly focused on climate change induced disaster and sustainable food security (Nandy and Islam, 2010). Few adaptation measures have also been promoted and subsequently applied in the south-western region of Bangladesh such a bid to reduce vulnerability of communities to climate 
change by increasing people's coping capacity (IPCC, 2001; RVCC, 2003; Schaerer and Ahmed, 2004) and application of some generic adaptation measures for the agriculture sector of Bangladesh (Ahammad, 2010). Habibullah et al., (1999) provided insights into on-the-ground adaptation techniques that might be followed for reducing vulnerability of crops under moderate to high saline affected conditions. Recently, Islam et al., (2015) has identified some effective adaptation measures to reduce the vulnerabilities of coastal agriculture in Bangladesh to climate change induced SLR. Review of existing literatures unveils that adaptation to climate change is necessary in addition to mitigate and avoid unacceptable impacts of climate change and SLR hazards. Therefore, formulating adaptation policies are emerging needs to minimize SLR impacts and to mitigate or reduce the vulnerability of agricultural sector. In this regard, the present study has importance to evaluate the people's perceptions to the effectiveness of different adaptation measures to combat the adverse impacts of climate change and SLR on agricultural vulnerabilities. The study also has importance to investigate the socio-economic aspects of the peoples to adapt with the adaptation measures. Evaluation of the people's perception on agricultural vulnerabilities to climate change and SLR with their socioeconomic aspects the present study has specific importance considering a few existing studies in these field.

\section{Materials and Methods}

The selection of the study area is purposive, based on various earlier studies which indicated that all locations were severely affected by several climatic hazards such as SLR induced storm surges, salinity intrusion to agricultural land and tidal flooding of the coast. The study has been conducted in the Villages of Shyamnagar Upazilla of Satkhira District in the south-western coast of Bangladesh (Fig. 1). The southern part of the study area is covered by the world largest mangrove forest. To conduct the questionnaire survey Gabura, Munshiganj and Koikhali Villages of Shyamnagar Upazilla are selected purposively considering their agricultural vulnerability to SLR. The maximum households of these three Villages are either directly or indirectly dependent on agriculture for livelihoods. All the selected study Villages are inundated by saline water every year as it is surrounded by river. The impacts of climate change and the changing effects of the coastal dynamics have negative effects to the coastal agricultural land and to its productivity. The methodology of this study started systematically with problem identification and ended by explaining the impacts of SLR induced hazards on agricultural adaptation options. The assumption of a 5 percent significance level resulted in an estimated sample size of 303 out of 1200 households. Samples were drawn proportionately from three villages (Yamane, 1967). The research is based on both secondary and primary data. The primary data were collected through key informant interviews, direct observations, household survey and as well as via focus-group discussions. Both descriptive and inferential statistics are used to analyze the data.

The descriptive statistics such as frequency, percentage, average and cross tabulation are also used to study the socio-economic conditions of the vulnerable people and the consequences of climate change induced hazard in agriculture sector. The chi-square test is applied to various demographic and socio-economic variables such as gender, age, education, agricultural land ownership, income and occupation against different adaptation options. It is assumed that such demographic and socio-economic variables have significant influence on the adoption of coping strategies against cyclones and induced surges. 


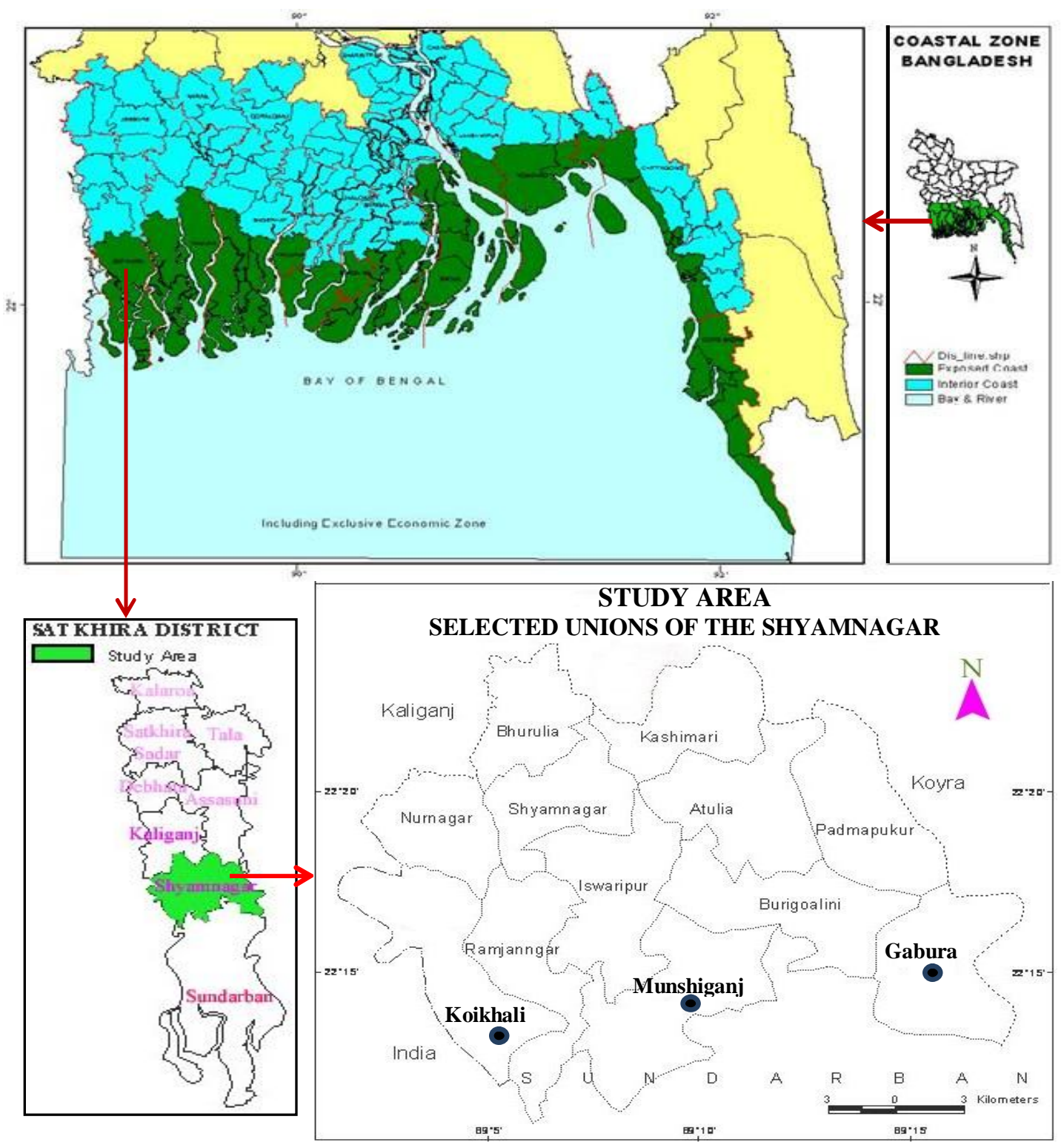

Fig. 1. Location of the study area. Dots show the study villages.

\section{Results and Discussion}

\section{Adaptation strategies to agricultural vulnerabilities in Bangladesh}

Coastal communities specially the peoples who are highly depends on coastal agriculture are facing much more vulnerabilities across the globe (Schaerer and Ahmed, 2004). Impacts of global climate change add to lower recovery or resilience of the natural system for human well-being and livelihoods (Rabbani et al., 2015). Various nature and impacts of climate change shocks affect coastal livelihoods differently and govern vulnerability and adaptive capacity of poor and marginalized groups in coastal areas (Nandy and
Islam, 2010). Due to the physiographic location of Bangladesh, the agriculture of the coast is highly vulnerable to the adverse impacts of climate change (Ahammad, 2010; Brammer, 2014). Some structural adaptation measures like construction of dam or dyke around agricultural land (Karim et al., 1999; Paul and Routray, 2011), proper drainage and management of the river embankment is very effective to control the prolonged inundation and logging of saline water (RVCC, 2003; Nandy and Islam, 2010; Paul and Routray, 2011). Similarly, considerations of some organizational and institutional measures such as providing government and NGOs facilities of credit, subsidy and insurance, ensuring the employment of farmers through capacity building 
and enhancing the innovative and technical support among the local peoples to face the challenges and vulnerabilities of climate change induced hazards in Bangladesh (Huq et al., 1996; Karim et al., 1999; Habibullah et al., 1999; Schaerer and Ahmed, 2004; Rabbani et al., 2015). Selection and implementation of some community based adaptation measures such as rainwater harvesting for drinking and irrigation, cultivation of saline tolerant crop varieties, practices of the floating and sarjan ${ }^{1}$ method of cultivation, vegetable cropping on shrimp farm embankment, and homestead gardening and forestry with mangrove trees also have a great importance to the economic sustainability of the peoples and to the development of agriculture (Huq et al., 1996; RVCC, 2003; Nandy and Islam, 2010). Some others homestead or local community-based adaptation practices like fishing in river or canal, crab fattening, duck rearing and livestock farming in household level also have a great importance to the economy of the marginal people as the alternative sources of income (Karim and Mimura, 2008; Ahammad, 2010; Rabbani et al., 2015).

Like the earlier study and analysis, the present study also finds that the selected adaptation options are very effective and essential to combat the vulnerabilities of the coastal agriculture of Bangladesh in the context of present and future climate change impact scenarios. Some community level and effective adaptation practices such as floating agriculture, embankment cropping, cultivation of saline tolerant crops, crab fattening and duck rearing to reduce the vulnerabilities of coastal agriculture are also shown here (Fig. 2) to understand the diversity of practices and strength towards longterm adaptation.

\section{Adaptation strategies and explanatory variables}

Considering the increasing impacts of global climate change, the peoples all over the coast who highly depends on agriculture have some traditional adaptation practices to adapt with climatic disaster, but the sustainability and effectiveness of such practices may vary over time and the scale of disaster itself. In a socioeconomic stratification approach, some find no relationships, while others come across positive association. Therefore, disagreement exists on which socio-economic variables should be considered. The traditional views follow a social stratification approach and use distinct groupings of relevant variables, while other approaches

1A method of cultivating year-round vegetables, vegetation on raised beds and cultivation of fish in ditches in the water-logged coastal areas. reject the appropriateness of using the cultural indicators of social stratification as true indicators of socio-economic association. The latter approach supports the use of social class analysis to explain variation in people's response to hazards and thus places emphasis on determining an individual's entitlement to ownership of land, economic activity and other socially available resources. Therefore, the present study follows the socio-cultural approach to determine the variations in people's perception to adapt with different adaptation strategies due to the variation in socio-economic factors.

\section{Age}

Vulnerabilities of the peoples who are highly depend on agriculture usually increases with age differentials. This study finds that increase of age increases the likelihood to select effective adaptation options to reduce the vulnerabilities of agriculture to climatic hazard; but experience may help as well to cope with vulnerabilities. About $48.2 \%$ of active household heads (30-60 years) and $34.0 \%$ of aged (60+ years) have the dependency to protect the forthcoming climate change and SLR vulnerabilities of agriculture by the construction of dam/ dyke around agricultural land based on their previous experience, compared with about $10.9 \%$ among the younger population $(<30$ years $)(p=0.000)$. Likewise, the likelihood of the selection of proper drainage to remove saline water logging as an adaptation options is comparatively higher $(p=0.000)$ among the active groups (49.5\%) and aged (33.0\%) than the younger ones (10.9\%). In contrast, tendency of the spreading of floating and sarjan method of cultivation as a new and effective coastal agricultural adaptation technique is higher among the active and younger groups than among the aged ( $p=0.027)$; as aged are unlikely to adapt with new innovative techniques. Choose of the adaptation options, employment of the farmers through capacity building is higher among the active group ( $p=0.048)$, while it is lower among the younger and aged groups. Similarly, to get the government and NGO facilities (such as subsidy, credit, insurance etc.) to reduce the vulnerabilities is higher among the aged group ( $p=0.018)$, while it is comparatively lower among the active and younger groups. As the active and younger peoples have the capability to do the hard work, they rely less on loan or credit systems, while due to the lack of income vulnerability of the aged peoples they have high expectations to the dependency on the government and NGO facilities. This ensures that increasing age erodes physical capability and increases the vulnerabilities to income and prolongs their dependency. 

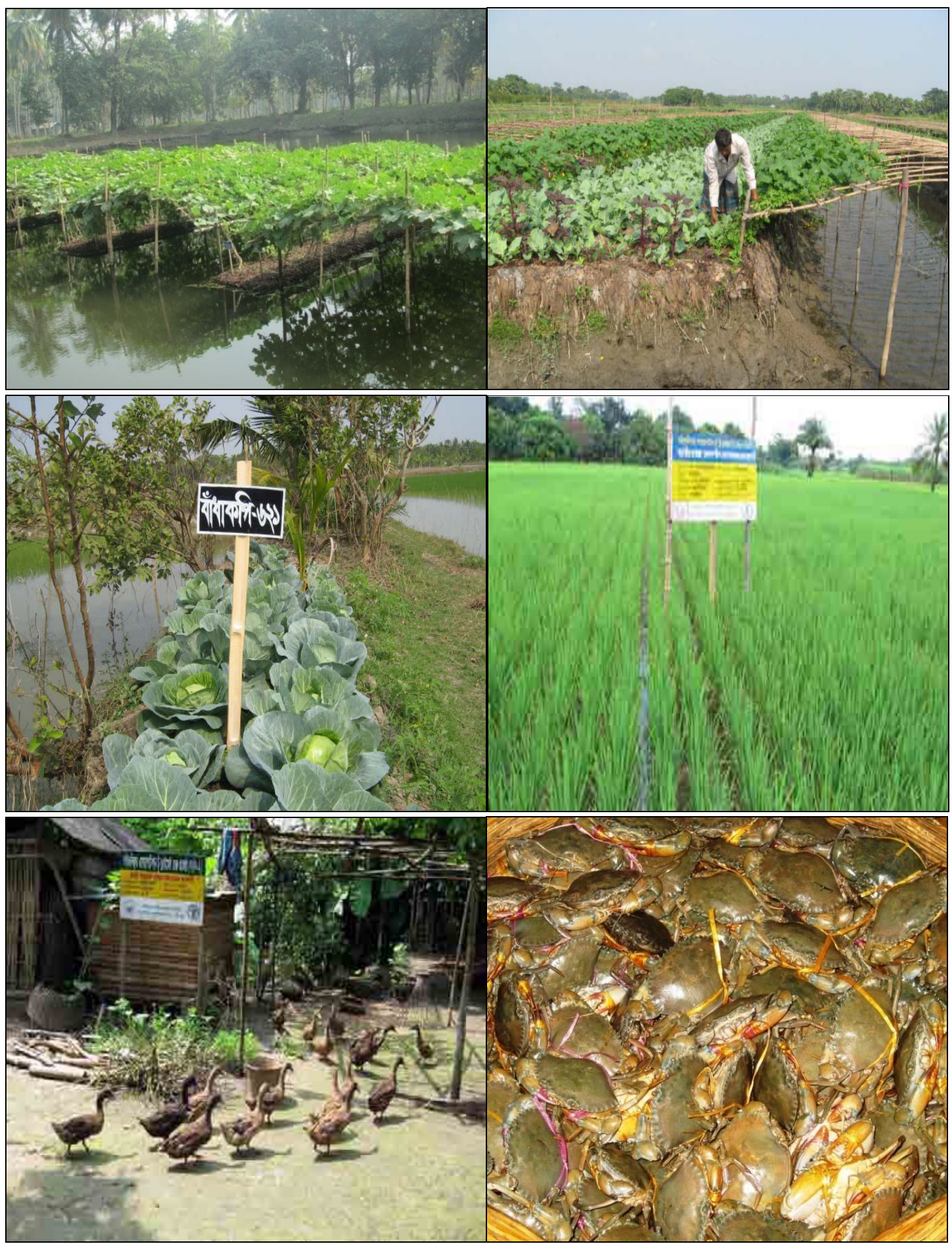

Fig. 2. Practices of some community-based adaptation options: Vegetable cultivation by floating dhap 2 technique(a), and sarjan method (b). Cropping on shrimp farm embankment (c) and saline resistant rice varieties (d). Duck rearing (e) and crab fattening (f) as alternative sources of income.

${ }^{2} \mathrm{~A}$ platforms or raft of floating agricultural practices for growing vegetables prevail in the wetlands using water hyacinth and aquatic weeds. 
Table 1. Summary of relationships between adaptation options to climate change induced SLR vulnerabilities with some explanatory variables.

\begin{tabular}{|c|c|c|c|c|c|c|}
\hline \multirow[t]{2}{*}{ Adaptation options } & \multicolumn{6}{|c|}{ Explanatory variables } \\
\hline & Age & Gender & $\begin{array}{l}\text { Education } \\
\text { level }\end{array}$ & $\begin{array}{l}\text { Agricultural } \\
\text { land }\end{array}$ & $\begin{array}{l}\text { Household } \\
\text { income }\end{array}$ & Occupation \\
\hline Construction of & $\chi^{2}=16.09$ & $\chi^{2}=11.85$ & $\chi^{2}=5.36$ & $\chi^{2}=13.91$ & $\chi^{2}=13.21$ & $\chi^{2}=16.05$ \\
\hline dam/dyke around & $\mathrm{df}=2$ & $\mathrm{df}=1$ & $\mathrm{df}=2$ & $\mathrm{df}=2$ & $\mathrm{df}=2$ & $\mathrm{df}=2$ \\
\hline agricultural land & $\mathrm{P}=0.000^{* * *}$ & $\mathrm{P}=0.001^{* *}$ & $\mathrm{P}=0.068(\mathrm{NS})$ & $\mathrm{P}=0.001^{* *}$ & $\mathrm{P}=0.001^{* *}$ & $\mathrm{P}=0.000 * * *$ \\
\hline Rainwater harvesting & $\chi^{2}=3.23$ & $\chi^{2}=2.61$ & $\chi^{2}=10.23$ & $\chi^{2}=6.42$ & $\chi^{2}=17.55$ & $\chi^{2}=5.49$ \\
\hline for drinking and & $\mathrm{df}=2$ & $\mathrm{df}=1$ & $\mathrm{df}=2$ & & $\mathrm{df}=2$ & \\
\hline irrigation & $\mathrm{P}=0.199(\mathrm{NS})$ & $\mathrm{P}=0.106(\mathrm{NS})$ & $\mathrm{P}=0.006^{* *}$ & $\mathrm{P}=0.040^{*}$ & $\mathrm{P}=0.000^{* * *}$ & $\mathrm{P}=0.064(\mathrm{NS})$ \\
\hline $\begin{array}{l}\text { Proper drainage to } \\
\text { remove saline water }\end{array}$ & $\begin{array}{l}\chi^{2}=18.98 \\
\mathrm{df}=2\end{array}$ & $\begin{array}{l}\chi^{2}=7.27 \\
\mathrm{df}=1\end{array}$ & $\begin{array}{l}\chi^{2}=18.18 \\
\mathrm{df}=2\end{array}$ & $\begin{array}{l}\chi^{2}=21.27 \\
\mathrm{df}=2\end{array}$ & $\begin{array}{l}\chi^{2}=14.46 \\
d f=2\end{array}$ & $\begin{array}{l}\chi^{2}=17.76 \\
\mathrm{df}=2\end{array}$ \\
\hline logging & $\mathrm{P}=0.000^{* * *}$ & $\mathrm{P}=0.007^{* *}$ & $\mathrm{P}=0.000^{* * *}$ & $\mathrm{P}=0.000^{* * *}$ & $\mathrm{P}=0.001^{* *}$ & $\mathrm{P}=0.000^{* * *}$ \\
\hline Control the & $\chi^{2}=4.06$ & $\chi^{2}=1.76$ & $\chi^{2}=4.60$ & $\chi^{2}=4.05$ & $\chi^{2}=12.56$ & $\chi^{2}=3.15$ \\
\hline aggression of new & $\mathrm{df}=2$ & $\mathrm{df}=1$ & $\mathrm{df}=2$ & $\mathrm{df}=2$ & $\mathrm{df}=2$ & $\mathrm{df}=2$ \\
\hline shrimp farm & $\mathrm{P}=0.131(\mathrm{NS})$ & $\mathrm{P}=0.184(\mathrm{NS})$ & $\mathrm{P}=0.100(\mathrm{NS})$ & $\mathrm{P}=0.132(\mathrm{NS})$ & $\mathrm{P}=0.002^{* *}$ & $\mathrm{P}=0.206(\mathrm{NS})$ \\
\hline $\begin{array}{l}\text { Control prolonged } \\
\text { inundation of saline }\end{array}$ & $\begin{array}{l}\chi^{2}=5.45 \\
\mathrm{df}=2\end{array}$ & $\begin{array}{l}\chi^{2}=1.99 \\
\mathrm{df}=1\end{array}$ & $\begin{array}{l}\chi^{2}=6.12 \\
\mathrm{df}=2\end{array}$ & $\begin{array}{l}\chi^{2}=10.43 \\
\mathrm{df}=2\end{array}$ & $\begin{array}{l}\chi^{2}=6.77 \\
\mathrm{df}=2\end{array}$ & $\begin{array}{l}\chi^{2}=8.49 \\
\mathrm{df}=2\end{array}$ \\
\hline water & $\mathrm{P}=0.066(\mathrm{NS})$ & $\mathrm{P}=0.158(\mathrm{NS})$ & $\mathrm{P}=0.047 *$ & $\mathrm{P}=0.005^{* *}$ & $\mathrm{P}=0.034^{*}$ & $\mathrm{P}=0.014^{*}$ \\
\hline $\begin{array}{l}\text { Cultivation of saline } \\
\text { tolerant HYV crops }\end{array}$ & $\begin{array}{l}\chi^{2}=2.65 \\
\mathrm{df}=2\end{array}$ & $\begin{array}{l}\chi^{2}=3.53 \\
\mathrm{df}=1\end{array}$ & $\begin{array}{l}\chi^{2}=6.44 \\
\mathrm{df}=2\end{array}$ & $\begin{array}{l}\chi^{2}=9.58 \\
\mathrm{df}=2\end{array}$ & $\begin{array}{l}\chi^{2}=3.49 \\
\mathrm{df}=2\end{array}$ & $\begin{array}{l}\chi^{2}=13.53 \\
\mathrm{df}=2\end{array}$ \\
\hline & $\mathrm{P}=0.266(\mathrm{NS})$ & $\mathrm{P}=0.060(\mathrm{NS})$ & $\mathrm{P}=0.040 *$ & $\mathrm{P}=0.008^{* *}$ & $\mathrm{P}=0.174(\mathrm{NS})$ & $\mathrm{P}=0.001^{* *}$ \\
\hline $\begin{array}{l}\text { Spreading of floating } \\
\text { and sarjan method }\end{array}$ & $\begin{array}{l}\chi^{2}=7.25 \\
\mathrm{df}=2\end{array}$ & $\begin{array}{l}\chi^{2}=3.67 \\
\mathrm{df}=1\end{array}$ & $\begin{array}{l}\chi^{2}=8.71 \\
\mathrm{df}=2\end{array}$ & $\begin{array}{l}\chi^{2}=17.36 \\
\mathrm{df}=2\end{array}$ & $\begin{array}{l}\chi^{2}=22.02 \\
\mathrm{df}=2\end{array}$ & $\begin{array}{l}\chi^{2}=26.04 \\
\mathrm{df}=2\end{array}$ \\
\hline of cultivation & $\mathrm{P}=0.027^{*}$ & $\mathrm{P}=0.055(\mathrm{NS})$ & $\mathrm{P}=0.013^{*}$ & $\mathrm{P}=0.000^{* * *}$ & $\mathrm{P}=0.000^{* * *}$ & $\mathrm{P}=0.000^{* * *}$ \\
\hline $\begin{array}{l}\text { Homestead } \\
\text { gardening and }\end{array}$ & $\begin{array}{l}\chi^{2}=3.99 \\
\mathrm{df}=2\end{array}$ & $\begin{array}{l}\chi^{2}=3.36 \\
\mathrm{df}=1\end{array}$ & $\begin{array}{l}\chi^{2}=7.87 \\
\mathrm{df}=2\end{array}$ & $\begin{array}{l}\chi^{2}=7.30 \\
\mathrm{df}=2\end{array}$ & $\begin{array}{l}\chi^{2}=4.51 \\
\mathrm{df}=2\end{array}$ & $\begin{array}{l}\chi^{2}=5.64 \\
\mathrm{df}=2\end{array}$ \\
\hline $\begin{array}{l}\text { forestry with } \\
\text { mangrove trees }\end{array}$ & $\mathrm{P}=0.136(\mathrm{NS})$ & $\mathrm{P}=0.067(\mathrm{NS})$ & $\mathrm{P}=0.020 *$ & $\mathrm{P}=0.026 *$ & $\mathrm{P}=0.104(\mathrm{NS})$ & $\mathrm{P}=0.060(\mathrm{NS})$ \\
\hline $\begin{array}{l}\text { Employment of } \\
\text { farmers through }\end{array}$ & $\begin{array}{l}\chi^{2}=6.08 \\
\mathrm{df}=2\end{array}$ & $\begin{array}{l}\chi^{2}=5.86 \\
\mathrm{df}=1\end{array}$ & $\begin{array}{l}\chi^{2}=11.23 \\
\mathrm{df}=2\end{array}$ & $\begin{array}{l}\chi^{2}=10.43 \\
\mathrm{df}=2\end{array}$ & $\begin{array}{l}\chi^{2}=11.13 \\
\mathrm{df}=2\end{array}$ & $\begin{array}{l}\chi^{2}=13.53 \\
\mathrm{df}=2\end{array}$ \\
\hline capacity building & $\mathrm{P}=0.048^{*}$ & $\mathrm{P}=0.015^{*}$ & $\mathrm{P}=0.004^{* *}$ & $\mathrm{P}=0.005^{* *}$ & $\mathrm{P}=0.004^{* *}$ & $\mathrm{P}=0.001^{* *}$ \\
\hline $\begin{array}{l}\text { Govt. and NGO } \\
\text { facilities (subsidy, }\end{array}$ & $\begin{array}{l}\chi^{2}=8.04 \\
\mathrm{df}=2\end{array}$ & $\begin{array}{l}\chi^{2}=7.27 \\
\mathrm{df}=1\end{array}$ & $\begin{array}{l}\chi^{2}=15.17 \\
d f=2\end{array}$ & $\begin{array}{l}\chi^{2}=9.12 \\
d f=2\end{array}$ & $\begin{array}{l}\chi^{2}=5.60 \\
\mathrm{df}=2\end{array}$ & $\begin{array}{l}\chi^{2}=7.13 \\
\mathrm{df}=2\end{array}$ \\
\hline credit, insurance etc.) & $\mathrm{P}=0.018^{*}$ & $\mathrm{P}=0.007 * *$ & $\mathrm{P}=0.001^{* *}$ & $\mathrm{P}=0.010 *$ & $\mathrm{P}=0.061(\mathrm{NS})$ & $\mathrm{P}=0.028 *$ \\
\hline
\end{tabular}

$\chi^{2}=$ Chi-square. $\mathrm{n}=303$; $* * * \mathrm{p}<0.0001 ; * * \mathrm{p}<0.01 ; * \mathrm{p}<0.05$; and NS = not significant; $\mathrm{df}=$ degrees of freedom

The study also reveals that tendency to cultivate of saline tolerant HYV (High Yielding Varieties) crops is higher among the young people (48.2\%) than the aged (33.3\%). This implies that aged people have less interest to the new variety of crops, which creates the crop failure and less production and increase the vulnerabilities. Likewise, effort to the control of the aggression of new shrimp farm and prolonged inundation of saline water into agricultural land is higher among the active group compare with aged and younger groups. Similarly, selection of rainwater harvesting for drinking, irrigation and homestead gardening and forestry with mangrove trees as the effective adaptation measures is higher among the active peoples, while the aged are not so feasible to adapt with this comparatively complex innovative measure. Hence, it is evident in this study (Table 1) that increasing age might lessen vulnerability of aged peoples who are depend on agriculture to some extent, but increased experience might help them to better understand the hazard risk to climate change and discourage them from adopting passive adaptation measures. In general, laggardness of the aged peoples to the new innovative and effective measures of agriculture makes them more vulnerable.

\section{Gender}

The present study reveals that due to physical ability about $65.0 \%$ of male headed have interest to construct dam or dyke around agricultural land to reduce the vulnerabilities $(p=0.001)$ than the female headed (28.1\%). Similarly, male headed is also highly feasible to choose the adaptation options such as proper drainage to remove the saline water from agricultural land (64.7\%; $\mathrm{p}=$ 0.007), employment of farmers through capacity building (64.6\%; $\mathrm{p}=0.015)$ and receiving credit or loan facilities from government and NGO authority (64.7\%; $p=0.007)$. The study also finds that female headed also feasible to some homestead base adaptive measures like rainwater harvesting for drinking water (29.7\%), homestead gardening and forestry with mangrove trees 
(29.0\%) and spreading of floating and sarjan methods of cultivation (29.4\%). Therefore, it is evident in this study (Table 1) that with the variations of the physical ability of the male and female there also have variations to cope with different adaptive measures to reduce the vulnerabilities of coastal agricultural, mainly based on the feasible criteria of the adaptive measures to the male and female.

\section{Education}

Selection and implementation of different adaptation measures to combat the vulnerabilities of coastal agriculture to climate change induced hazards have direct relation with the education level of the peoples. According to the present study, majority of the household heads having primary and secondary level of education (56.8\%) are agree to proper drainage for removing saline water logging as an adaptation options, while it gradually decreases among illiterate (29.0\%) and college or higher educated $(7.6 \%)$ household levels $(\mathrm{p}=0.000)$. Likewise, taking the government and NGO facilities such as credit and insurance $(p=0.001)$, employment of farmers through capacity building $(\mathrm{p}=0.004)$, rainwater harvesting for drinking and irrigation $(p=0.006)$, spreading of floating and sarjan method of cultivation $(p=0.013)$, homestead gardening and forestry with mangrove trees ( $p=0.020)$, cultivation of saline tolerant HYV crops $(p=0.040)$ and controlling the prolonged inundation of saline water $(p=0.047)$ is higher among the household heads with primary and secondary education and gradually decreases with illiterate and college or higher education. As the higher educated peoples are not directly involved with agriculture for their income so they have little interest to marginal level of adaptation measures. Interestingly, consideration of the construction of dam or dyke around agricultural land and controlling the aggression of new shrimp farm as the adaptation measures is higher among the illiterate peoples because of their involvement to these types of marginal level labor base activity. It is evident in the study that agriculture as a main economic activity of the primary and secondary education level peoples has high involvement to consider the maximum adaptation measures (Table 1) to reduce the vulnerabilities of coastal agriculture to climate change induced SLR.

\section{Ownership of agricultural land}

The present study reveals that maximum of the households of the study area are small and medium level farmers, the second highest households are the landless farmers and their number is increasing day by day due to the increasing of vulnerability of agriculture. There also have some households who are large farmer, they are not directly involved with agriculture and they are mainly landlord. Likewise, the small and medium level farmers have highest tendency to consider the proper drainage for removing saline water from agricultural land ( $54.5 \% ; p=0.000)$ and spreading of floating and sarjan method of cultivation (54.8\%; $\mathrm{p}=0.000$ ) as the adaptation measures than the landless (31.4 \% and 31\%, respectively) and the large farmers $(7.6 \%$ and $7.9 \%$, respectively).

Similarly, construction of dam or dyke around agricultural land $(\mathrm{p}=0.001)$, employment of farmers through capacity building ( $p=0.005)$, controlling of the prolonged inundation of saline water $(p=0.005)$ and cultivation of saline tolerant HYV crops $(p=0.008)$ is higher among the small and medium level farmers than the landless and large farmers. The small and medium level farmers also have highest tendency to consider the government and NGO facilities ( $p$ $=0.010$ ), homestead gardening and forestry with mangrove trees $(p=0.026)$ and rainwater harvesting for drinking and irrigation $(p=0.040)$ as the adaptive measures than the landless and large farmers. In contrast, small and medium level farmers have less interest to the adaptive measure controlling the aggression of new shrimp farm considering their small land size but landless and large farmers show more interest to this respectively for selling more labor and high income. Finally, the present study finds that (Table 1) small and medium level farmers have the highest capacity to take the different adaptive measures than the landless and large farmers to combat the vulnerabilities of agriculture.

\section{Household income}

The present study finds that most of the households of the study area are middle income groups who are directly involve in agriculture, the second highest households are the lower income groups and their number is increasing day by day due to the increasing vulnerability of agriculture. Likewise, the middle-income groups have high capability to harvest the rainwater for drinking and irrigation (53.8\%; $\mathrm{p}=0.000)$ and spreading of floating and sarjan method of cultivation (53.7\%; $\mathrm{p}=0.000$ ) as the adaptation measures than the lower income groups (30.0\% and $30.1 \%$, respectively) and the higher income groups (10.2\% and $9.9 \%$, respectively). Similarly, construction of dam or dyke around agricultural land $(p=0.001)$, proper drainage to remove saline water from agricultural land $(p=0.001)$, controlling the aggression of new shrimp farm ( $p$ $=0.002$ ) and employment of farmers through capacity building $(p=0.004)$ is higher among the medium income groups than the lower and higher income groups. The medium income groups also have capability to control of the 
prolonged inundation of saline water $(\mathrm{p}=0.034)$ as an adaptation measure than the lower and higher income groups. In contrast, medium income groups have less interest to some adaptive measures such as cultivation of saline tolerant HYV crops, homestead gardening and forestry with mangrove trees considering the limitations of their income capability. Therefore, the lower income groups have a high interest to get the facilities from government and NGOs due to their low income and poverty. The large income group also shows the little interest to the adaptation measures for agriculture because their income source and economic activity is not directly involved with agricultural activities. Finally, the present study finds that (Table 1) medium income groups have the highest capability to adopt different adaptive measures than the lower and higher income groups to protect the vulnerabilities of agriculture.

\section{Occupation}

This study reveals that the peoples who work on his own agricultural farm have highest capacity to consider the selected adaptation measures than the peoples who are selling their labor to the others agriculture and the peoples who are involved in the non-agricultural activities. Similarly, the peoples who work on his own agricultural farm have high capacity to construct dam or dyke around agricultural land (54.8\%; $\mathrm{p}=$ 0.000 ), proper drainage to remove saline water from agricultural land (55.1\%; $p=0.000)$ and spreading of floating and sarjan method of cultivation (55.4\%; p $=0.000$ ) as adaptation measures than the peoples who work as day labor in agriculture $(29.5 \%, 29.4 \%$ and $29.7 \%$, respectively) and the peoples who are doing nonagricultural activities (8.8\%, 8.9\% and $8.6 \%$, respectively). Likewise, the interest to the cultivation of saline tolerant HYV crops ( $p=$ 0.001 ) and the employment of the farmers through capacity building $(\mathrm{p}=0.001)$ is higher among the peoples who work on his own agricultural farm than the peoples who work as day labor in agriculture and the peoples who are involved in non-agricultural activities. The peoples who work on his own agriculture farm also have interest to control prolonged inundation of saline water $(\mathrm{p}=0.014)$ and taking facilities from government and NGOs $(p=0.028)$ such as credit and insurance as the adaptation measures to reduce the damages of agriculture in the time of hazards. In contrast, the peoples who work on his own agriculture farm have less interest to adopt some adaptive measures such as rainwater harvesting for drinking and irrigation, controlling the aggression of new shrimp farm and homestead gardening and forestry with mangrove trees considering their rice field base intensive agricultural activities. Therefore, the peoples who work as day labor in agriculture and who are involved in non-agricultural activities have interest to these options regarding their variations and vulnerabilities in occupation. Finally, it reveals in this study that (Table 1) the peoples who work on his own agricultural farm have the highest opportunity to consider the different adaptive measures than the peoples who work as day labor in agriculture and the peoples who are involved in non-agricultural activities to face the vulnerabilities of agriculture to the climatic hazards.

\section{Conclusion}

The present study finds that climate change and induced SLR have overwhelming impacts on agriculture, environment as well as on people's livelihoods of coastal Bangladesh. These impacts depend not only on the location exposure and increasing intensity of SLR hazards, but also linked with several demographic, socio-economic, cultural and other variables. People's perception about the adaptation strategies such as construction of dam or dyke around agricultural land, rainwater harvesting, drainage management to control the inundation and logging of saline water, control the aggression of new shrimp farm cultivation of HYV and saline tolerant crops, is very effective to reduce the vulnerabilities of coastal agriculture in the context of climate change and SLR hazards in Bangladesh. The study also finds that some community-based adaptation strategies such as micro financial support from government and NGOs, floating agriculture and homestead gardening, embankment cropping, duck rearing and crab fattening as the alternative sources of income and employment for the peoples have significant influences to reduce the vulnerabilities of coastal agriculture in Bangladesh. This study confirms that the demographic and socio-economic factors such as gender, age, education, land ownership, income and occupational variations of the peoples have a high dependency and interrelations with the adaptation options for agriculture considering the time and intensity of climate change and sea in level induced hazards in coastal Bangladesh. Like the vulnerability of the environment of coastal agriculture the demographic and socio-economic indicators of the peoples also vulnerable to the changing climate and its impacts in Bangladesh. As the coastal agriculture of Bangladesh is highly vulnerable to various climate change and SLR induced hazards, so selection and implementation of the above mentioned adaptive measures is very important and necessary considering the variations of demographic and socio-economic indicators considering coastal setting. 


\section{References}

ADB. 1994. Climate Change in Asia: Bangladesh Country Report. Asian Development Bank, Manila. pp. 128-214.

Ahammad, A.U. 2010. Reducing vulnerability to climate change: the pioneering example of community-based adaptation in Bangladesh. CGC-CARE Bangladesh, Dhaka. p. 156.

Brammer, H. 2014. Bangladesh's dynamic coastal regions and sea-level rise. Climate Risk Manage. 1: 51-62.

Habibullah, M., Ahmed, A.U. and Karim, Z 1999. Assessment of food grain production loss due to climate induced enhanced soil salinity. pp. 55-70. In: Huq, S., Karim, Z, Asaduzzaman, M., Mahtab, F. (eds) Vulnerability and Adaptation to Climate Change for Bangladesh. Springer, Dordrecht.

Huq, S., Ahmed, A.U. and Koudstaal, R. 1996. Vulnerability of Bangladesh to climate change and sea level rise. pp. 347-379. In: T.E. Downing (Ed.), Climate Change and World Food Security, NATO ASI Series, I 37, Springer-Verlag, Berlin, Hiedelberg.

IPCC. 2001. Climate change 2001: Impacts, adaptation and vulnerability, contribution to working group-II to the Third Assessment Report, MoCarthy. pp. 574-578.

Islam, M.A., Paul, S.K. and Hassan, M.Z. 2015. Agricultural vulnerability in Bangladesh to climate change induced sea level rise and options for adaptation: a study of a coastal Upazila. J. Agric. Environ. Int. Dev. 109 (1): 19-39.

Karim, M.F. and Mimura, N. 2008. Impacts of climate change and sea-level rise on cyclonic storm surge floods in Bangladesh. Glob. Environ. Change. 18 (3): 490-500.

Karim, Z., Hussain, S.G. and Ahmed, A.U. 1999 Climate Change Vulnerability of Crop Agriculture. pp. 39-54. In: Huq, S., Karim,
Z, Asaduzzaman, M., Mahtab, F. (eds) Vulnerability and Adaptation to Climate Change for Bangladesh. Springer, Dordrecht.

Nandy, P. and Islam, M.A. 2010. Climate resilient coastal zone development in Bangladesh: participatory governance for common resources management. pp. 58-72. In: Ramanathan, A.L., Bhattacharya, P., Dittmar, T., Prasad, M.B.K., Neupane, B.R. (eds) Management and Sustainable Development of Coastal Zone Environments. Springer, Dordrecht.

Paul, S.K. and Routray, J.K. 2010. Flood proneness and coping strategies: the experiences of two villages in Bangladesh. Disasters. 34 (2): 489-508.

Paul, S.K. and Routary, J.K. 2011. Household response to cyclone and induced surge in coastal Bangladesh: coping strategies and explanatory variables. Nat. Hazards. 57: 477-499.

Rabbani, M.G., Rahman, A.A., Shoef, I.J. and Khan, Z.M. 2015. Climate Change and Food Security in Vulnerable Coastal Zones of Bangladesh. pp. 173-186. In: Habiba, U., Hassan, A., Abedin, M., Shaw, R. (eds) Food Security and Risk Reduction in Bangladesh. Disaster Risk Reduction (Methods, Approaches and Practices). Springer, Tokyo.

RVCC. 2003. Report of a Community Level Vulnerability Assessment Conducted in Southwest Bangladesh. Reducing Vulnerability to Climate Change, CARE, Bangladesh. pp. 26-35.

Schaerer, C. and Ahmed, A.U. 2004. Adaptation to climate change in vulnerable communities: lessons from practice in southwestern Bangladesh. Proceedings of workshop at COP9, Milan. pp. 19-21.

Yamane, T. 1967. Statistics: An Introductory Analysis (2nd Ed.), Harper and Row, New York. pp. 221-224. 